\section{Multiple Magnet Aspiration into the Lungs in an Adolescent}

Sir,

In recent years, powerful neodymium magnets have been sold as table-top toys and stress relief products for adults. Ingested magnets have been recognised as an important cause of serious gastrointestinal morbidity and mortality, resulting from the magnets attracting each other through the bowel wall, causing obstruction, perforations, haemorrhage, fistula formation, and sometimes death. There have been limited published reports of magnets being aspirated into the respiratory tract as inhaled foreign bodies (FB). ${ }^{1-3}$ We document the first report of multiple magnet aspiration intothe lungs in an adolescent.

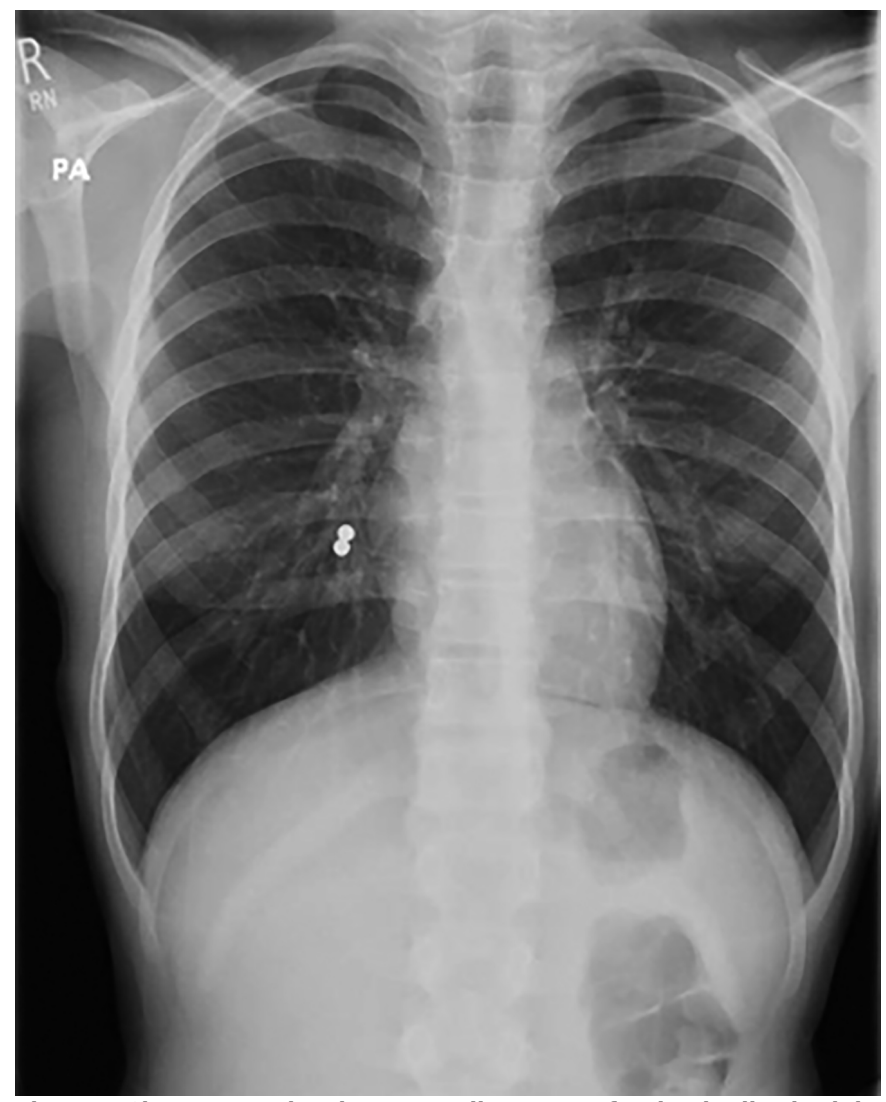

Figure1: Chest X-ray showing two radio-opaque foreign bodies in right lowerlobe bronchus.

A 12-year girl presented a few hours after having accidently inhaling two small magnetic balls at school whilst pretending to have a tongue piercing; it was reported that her friend had tried a similar trick the previous day and had attended the hospital following ingestion of magnets. She was asymptomatic at presentation. Chest $\mathrm{X}$-ray (Figure 1 ) revealed two radiodense foci in the right paracardiac region, in keeping with foreign bodies located within the right lower lobe bronchus. She was transferred to the regional surgical centre, where the FBs were retrieved through endoscopy-assisted rigid bronchoscopy, approximately 15 hours after the magnets had been aspirated. The magnets were noted to be partially stuck to each other and mild sloughing was seen at the site of lodgement. A telephone consultation, after one month, confirmed that she remained well.

There have been very few published reports of multiple magnet aspiration into the airways. A meta-analysis of 174 papers published over a 30 years period (1978-2008) found 13 cases of magnetic FBs in the airway, most of which were single magnets lodged in the nostrils, where accessibility for removal is far easier than for FB lodged deeper down the airway or in the lungs. ${ }^{4}$ There have been no previous published reports of multiple magnets being aspirated into the lungs.

The unique risk from the aspiration of multiple small magnets is that of pressure necrosis and consequent complications, where two or more magnets attract through mucosal surfaces, as seen in multiple magnet ingestions into the gastrointestinal tract. Suspected cases should be diagnosed by chest X-ray, and magnets be removed through endoscopy-assisted rigid bronchoscopy with urgency. ${ }^{5}$

\section{PATIENT'S CONSENT:}

Informed consent has been obtained from the parent of the patient to publish the data concerning this case.

\section{CONFLICT OF INTEREST:}

The authors declared no conflict of interest.

\section{AUTHORS'CONTRIBUTION:}

SPP: Concept, manuscript preparation, literature search, submission and correspondence.

AA: Data collection, initial case study summarisation, obtaining electronic images and literature search.

PAH: Concept, manuscript editing scientifically and as native English speaker, and providing expertopinion on management.

\section{REFERENCES}

1. Ke KJ, Liu DB, Huang ZY, Xu JJ. One case of rare tracheobronchial foreign body (fusiform magnet) successfully removed through bronchoscopy in a child. Zhonghua Er Bi Yan Hou Tou Jing Wai Ke Za Zhi 2013; 48:848. doi: 10.3760/cma.j.issn.1673-0860.2013.10.014.

2. Narang S, Joshi J, Vasudevarao SB, Rao S. Use of a surface magnet in the extraction of another magnet aspirated into the bronchus of a 7-year-old girl. BMJ Case Rep 2019; 12:e230107. doi: 10.1136/bcr-2019-230107.

3. Xu J, Liu D, Huang Z, Ke K. Small magnet aspiration as a pediatric emergency: A case report. Int J Clin Exp Med 2015; 8:19561-5. doi: 10.1136/bcr-2019-230107.

4. Foltran F, Ballali S, Passali FM, Kern E, Morra B, Passali GC, et al. Foreign bodies in the airways: a meta-analysis of published papers. Int J Pediatr Otorhinolaryngol 2012; 76:S12-9. doi: 10.1016/j.ijporl.2012.02.004. 
5. Paul SP, Irwin AC, Heaton PA. Dangerous ingestions in children. J Fam Health 2015; 25:16-9.

Siba Prosad Paul, Amna Ahmad and Paul Anthony Heaton Department of Paediatrics, Yeovil District Hospital, Yeovil, UK
Correspondence to: Dr. Siba Prosad Paul, Department of Paediatrics, Yeovil District Hospital, Yeovil, BA21 4AT, UK E-mail: siba@doctors.org.uk

.

Received: July 04, 2020; Revised: August 07, 2020;

Accepted: August 17, 2020

DOI: https://doi.org/10.29271/jcpsp.2021.06.754 